\title{
The Location of a Library's Science Collection
}

\begin{abstract}
The arguments for and against centralization of a library's science collections-the weight of which seems to favor centralization-are reviewed. Considerations of importance in deciding location include size, use, proximity, function, and comprehensiveness of the collection. Office collections grow into departmental libraries, which in turn grow into science divisional libraries. Until book collections become formal libraries, however, they can be used to supplement formal library service. Increasing emphasis upon multidisciplinary research argues for greater centralization of science libraries.
\end{abstract}

HE ARGUMENTS FOR AND AGAINST centralization or decentralization of a library's science collections have been considered before. Miller ${ }^{1}$ and Shera ${ }^{2}$ argue rather successfully for centralization from the library administrator's point of view. Nicholson $^{3}$ summarizes the factors for centralization very nicely as follows:

Factors in favor of centralization of an institution's library resources include economy (the avoidance of some salary costs, of certain duplications of books, of multiple card catalogs, of separate physical quarters, equipment, and maintenance), the convenience to users where subject interests cut

${ }^{1}$ Robert A. Miller, "Centralization vs. Decentralization," Bulletin of the American Library Association, XXXIII (1939), 75-9, 134-5.

'Jesse H. Shera, "How Much Is a Physicist's Inertia Worth?" Physics Today, XV (August 1961), 42-3.

${ }^{3}$ Natalie N. Nicholson, "Centralization of Science Libraries at Johns Hopkins University," In Studies in Library Administrative Problems (New Brunswick N.J.: Graduate School of Library Service, Rutgers, The State University, 1960). pp. 134-5.

$\mathrm{Mr}$. Waddington is Coordinator of Science Collections, Dartmouth College Libraries. across several disciplines, better preservation of materials, more complete reference an increase in total resources available to all users alike, at a more reasonable cost.

On the other hand, arguments for deservices, and greater efficiency in certain operative procedures. In essence, it provides centralization seem not to be as well formulated. Wells ${ }^{4}$ bases his case for decentralization on convenience to the user, and Marron $^{5}$ recognizes the fact that economics favor centralization and scientists' reading habits favor decentralization. The compromise of duplication in microforms is not yet a workable possibility because of lack of sufficient titles in these media. The need for close proximity between laboratory and the library in the scientific disciplines, however, can best be shown as an out-growth of three factors. First, some laboratory work requires almost constant supervision so

tD. A. Wells, "Individual Department Libraries vs. Consolidated Science Libraries." Physics Today, XIV (May 1961), 40-41.

"Harvey Marron, "Science Libraries Consolidated/Departmental?" Physics Today, XVI (July 1963), 34-9. 
that a research worker can leave his work only for very short periods. Second, research work in the laboratory sometimes requires consultation of the literature during the progress of an experiment when leaving the building for a prolonged period of time could ruin the experiment and months of previous work. Finally, the pace of modern science is so fast that, in general, the scientist will have great need to use the periodical literature which because of its bulk (multiple bound volumes) and its nature is best left stored in a library situation with its corresponding abstracting and indexing services. It should also be noted that the advocates of centralization always assume that the central library situation is efficient. In cases where this is not so, it could be much easier to run an efficient branch library or to improve its efficiency than to wait for such improvement to take place at the central library.

The key to a solution to this problem lies in an analysis of the library's functions. The library must be viewed first as part of a total system which considers both the book collections and the users of these collections as part of a whole. Five factors seem to be of significance when considering the location of science collections: frequency of use, size, proximity to the laboratories, kind of use, and completeness. One important measure of a book's value to the user or to the institution is the frequency with which it is used. To arrive at a reasonable utilization of library materials, the books and journals must be used a certain number of times within a given unit of time. Two variables play a role when trying to increase this frequency of use per item: (1) the size of the collection, (2) the distance or proximity of the book collection from the related scientific laboratory or the chief group of users. The former favors centralization; the larger the size the more economic the library unit. The latter favors decentralization; the closer the collection is to the users the greater the possible use of the collection. Two other factors also play a role in trying to decide the best location for any given item-the type of use made of the book or journal and the completeness of the collection. Certain kinds of books and journals are only useful or find their best use in conjunction with laboratory experiments. For example, Index kewensis plantarum phanerogamarum nomina ... (Oxonii, eprelo Clarendoniano, 1895); Handbook of Chemistry and Physics (Cleveland, Chemical Rubber Co., current ed.); International Tables for X-ray Crystallography (Birmingham, England, International Union of Crystallography, Kynoch Press, 1952-62).

In a library situation the size of the collection must be planned within certain limits. To provide minimum service, specifically eighty-eight to ninety hours a week of circulation and reference coverage, a branch library must reach a certain critical size. This size-necessary to justify a staff large enough to provide the above coverage and yet provide a sufficient amount of work-is not capable of precise definition. It will vary with the nature of the collections and the program it serves but may minimally be about ten thousand to twenty thousand volumes. For example, libraries with holdings in the applied sciences (e.g., engineering) can be on the smaller end of the spread since considerably more reference work is usually required and performed. Personnel for such a minimum library would consist of one professional librarian and one and one-half or two clerical assistants. The type of services included would be both of the housekeeping kind and of a reference nature. The former makes the material within the library more accessible through circulation control, prompt reshelving, periodic inventories, recall of overdue items, a card catalog, a periodical check-in file, etc., and provides a permanent point of contact with other 
libraries in the system. References would include guidance in locating materials within this library and the rest of the library system complex through use of the card catalog; abstracting and indexing services; and reference books. Literature searches and instruction in the use of the library and the literature could be provided as requested. Faculty members benefit from prompt attention in making selections, ordering, and processing of items in areas of their individual specialties.

Consideration must also be given to recent changes in scientific research trends. Most departmental libraries are the product of a former more precise division between scientific disciplines and the need for close proximity of books and laboratories. The growth of interdisciplinary research, ${ }^{6}$ however, the rapidity with which changes occur, the great increase in the quantity of literature being published, the construction of interdisciplinary laboratories, ${ }^{7}$ and the growing application of computers to library routines seem to indicate the need for re-evaluation of the usefulness and economy of departmental libraries to one oriented subject. The larger the department involved, the greater is the pressure to duplicate material in related subject areas already in other libraries on campus. It is no longer possible for an individual discipline to claim exclusive need and use of library materials in one subject area. These developments tend to favor greater centralization.

One scheme for determining the best location for library materials might be based upon consideration as to what books and journals are properly library material and what should be of primarily departmental or individual responsibility. Libraries that have science collections below the critical size might centralize all their material in a central li-

\footnotetext{
- Philip H. Abelson, "Trends of Scientific Research," Science, CXLIII (1964), 218-23.

" EFL College Newsletter, No. 4, May 1964.
}

brary and encourage patrons to use departmental and individual-owned collections as a supplement. Once science collections reach a critical size, location of this material in a separate central science library, again supplemented by departmental or individual collections, can be considered. Finally, in very large institutions, the main science collections should continue to be centrally located in a science library. Departmental reading room collections, justified by frequency of use, which reach a critical - size, then can be incorporated into the library system as branch libraries covering one specific discipline. These libraries for the most part probably would include only duplicate collections of items already in the science library. A host of devices and procedures must be included in any library system's over-all plans to provide greater flexibility aimed at maximum convenience for the user within the economic limits of the institution. Material of use only within a laboratory situation should be owned by the department and should be added to the library's collection only when necessary to complete the collection.

Material of a nature that can or must be used in both the laboratory and the library, or that is used by two or more disciplines when located in the library must be accessible to users through xerography, telephone reference service, and a messenger service. An adequate number of individual studies and carrels should be available to facilitate use of books and journals during extensive periods of research in the library. Material located in the library must be supervised during the time the library is open, and library hours should be tailored to the needs of all users. Researchers having special and justified needs should have the possibility of access to the science collections for limited time periods outside of library hours. For example, a researcher wishing to work during a holiday weekend might be able to sign out 
a key to the library on assumption of responsibility for the collection during that period of time. Cooperation between the individual scientists, the departments, and the library in collecting material is essential. As individual collections increase to an unmanageable size, they should cumulate into departmental reading rooms, and when these reach a critical size the collections should fade into control and supervision by the library. The location of science collections, departmental or library owned, should be as central as possible to all departmental laboratories and connected by passageways if necessary. An ideal solution to this problem would seem to be the following description of a sciences building complex:

. . . a great wheel, or pentagon, in which the science library would be the hub, the radiating spokes the major disciplinesphysics, mathematics, chemistry, the biological sciences-and the rims the laboratories."

Finally, if the library's users include students, a strong argument can be made for centralizing science collections for their convenience. They will be taking courses in a variety of subjects, and in an era when ever-increasing quantities of materials must be covered in each subject any time saved for students would be an educational advantage.

In conclusion it should be stressed that a university or college library's main function is to provide the user with those books that have a frequency of use that is so low, or a cost that is so high, as to prohibit individual purchase or ownership and to increase the educational value of each item by adding to the completeness of the collection. Within those sciences that need to use books and journals in a laboratory situation it is necessary that individual scientists and departments assume ownership and responsibility for some types of library materials.

\footnotetext{
8 Shera, op. cit., p. 42.
}

\section{University of Hawaii}

(Continued from page 382 )

location of materials charged within five minutes at most. Three professional positions have been transferred from the circulation department to other places where they are needed. Two of these positions were filled and the personnel are now working in other departments, the third is in process of being filled in another department.

Caveat: This is not a generalization about computer charging. It is a factual report on the system as it was actually applied at the University of Hawaii. It may very well be that some system still to come and some machine configuration still to come may give us better control of loans for less money, but that remains for the future.

This is not a condemnation of the use of computers in libraries when suitable. We have, in fact, just completed the systems work and programing, including two dry runs, and have converted to computer handling of our accounting records for book purchases, which have to be distributed against some fifty accounts. The time studies on this application indicate that the use of a key punch for two hours per day plus the use of a 1401 computer for not more than ten minutes per month will save us a net of somewhat more than fourman-years while giving us better and more prompt control of our book expenditures. As fast as we can develop, or anyone can show us, other applications that will in fact release time for library services or money for books we will put them into operation. This, however, requires rigorous systems work and careful costing so that we can be reasonably certain that the change will result in an improvement. The kind of reliable and helpful information that is needed is not provided by articles such as the one under discussion. 